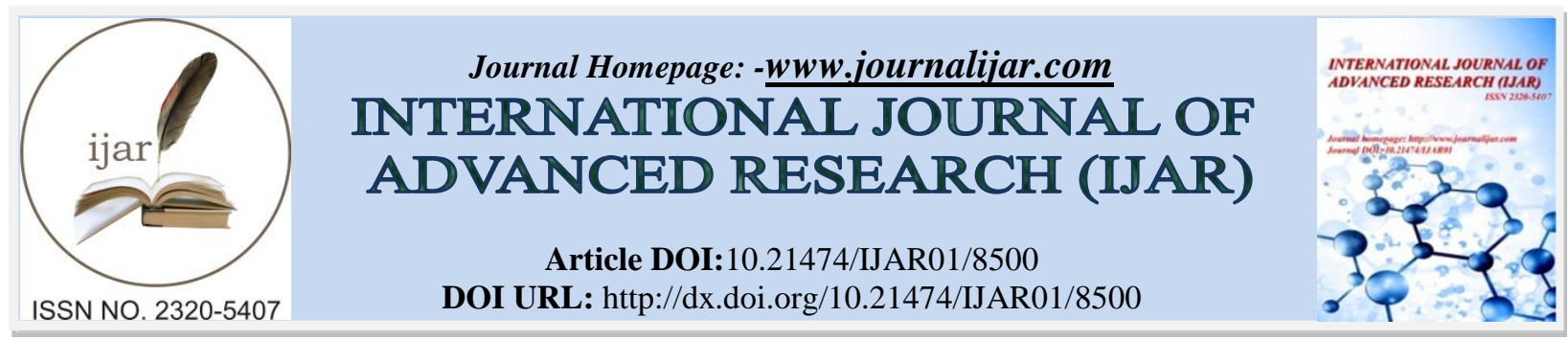

RESEARCH ARTICLE

\title{
REVERSE SURAL ARTERY FLAP; TEN YEARS EXPERIENCE AT A TERTIARY CARE CENTRE.
}

\author{
Mir Mushtaq, Bashir Ahmad Bhat, Mushtaq Ahmad Bhat, Rifut Ara and Shabir Iqbal. \\ Department of plastic surgery SHMS hospital Srinagar Jammu and Kashmir India.
}

\section{Manuscript Info}

\section{Manuscript History}

Received: 05 December 2018

Final Accepted: 07 January 2019

Published: February 2019

\section{Key words:-}

Distally based Sural flap; distal leg, heel and foot defects; reconstruction of foot.

\begin{abstract}
Soft tissue management around the lower third of the leg and foot presents a considerable challenge to the reconstructive plastic surgeon. The options in this region are limited. A durable flap is the preferred option for coverage of such defects. This study was conducted over a period of 10 years to evaluate the efficacy of distally based Sural flap in coverage of the lower third of leg, ankle and foot defects.

Material and Methods: A retrospective study was conducted in the department of Burns, Plastic, and Reconstructive surgery GMC Srinagar. The patients who underwent treatment from March -2008 to Feb -2018 were the subjects of study. Distally based sural fasciocutaneous flap was used for coverage in all cases and its survival, successful coverage of the defect and donor site morbidity studied. Results: Out of 100 flaps, 80 showed complete survival (80\%). Partial flap loss (up to one third but less than half of the flap) was found in 3 patients (3\%), marginal flap necrosis in 4 patients (4\%), venous congestion developed in 5 patients (5\%) and complete loss in 4 patients (4\%) with extensive heel injury.

Conclusions: The distally based sural flap is a versatile and reliable flap for the coverage of soft tissue defects of the distal lower extremity. The procedure is done as a single stage; the dissection is easy with short operating time and minimal morbidity.
\end{abstract}

Copy Right, IJAR, 2019,. All rights reserved.

\section{Introduction:-}

The management of soft tissue defects around the lower third of the leg,ankle and foot poses a considerable challenge to the reconstructive surgeon because of the composite tissue defects, inadequate and tight local tissues and poor circulation.(1) Tendons, bone or hardware are frequently exposed because of the thinness of subcutaneous tissues, making skin grafting a poor option.(2) A durable flap with good skin texture, reliable vascularity, good arc of rotation, ease of dissection and minimum donor site morbidity is the most desired option for coverage of such defects. $(3,4)$ The different local flaps for hind foot defects including dorsalis pedis artery flap, abductor hallucis and abductor digiti minimi muscle flaps, have inadequate tissue and a limited arc of rotation thereby limiting their frequent use. Medial planter artery flap is an ideal option for the weight bearing heel but its involvement in trauma frequently precludes its use.(5) Locoregional flaps for lower leg and ankle defects such as peroneal artery flap, anterior and posterior tibial artery flaps have the disadvantage of sacrificing a major artery in an already traumatized leg.(6) Supramalleolar flap is another option but its reliability is questionable in case of vascular compromise.(7) 
Perforator flaps are a recent addition in the armamentarium of plastic surgeon for reconstruction of lower third and hind foot defects. Free tissue transfer is ideal option in most circumstances but the need for microsurgical expertise and prolonged operating time remain its disadvantages.(8) In 1992, Masquelet et al. described the use of the neurocutaneous flap for reconstruction of soft tissue defects of the distal third of the leg., which was commonly referred to as"reverse sural artery island flap" and has become an acceptable and routine technique for lower limb reconstruction(9).To facilitate safe usage of this flap in difficult and special conditions, several modifications have been made to the technique, such as delaying, exteriorizing the pedicle and a wider than usual pedicle, mobilizing the peroneal perforator in the intramuscular septum, supercharging, cross-leg sural flap, leaving a skin extension over the pedicle, and harvesting a midline cuff of the gastrocnemius muscle with the flap The objective of this study was to evaluate the efficacy of distally based sural flap.

\section{Material and Methods:-}

The study was retrospective in nature and was conducted in the department of Burns, Plastic, and Reconstructive surgery GMC Srinagar. The patients who underwent treatment from March -2008 to Feb -2018 were the subjects of study. Preoperatively the age and sex of each patient, cause, size and site of the defect, time since injury, exposure of bone or tendons, presence of chronic osteomyelitis, and any co-morbid conditions were noted. Per operatively dimensions of the flap, level of proximal flap margin where designed on the leg, island or paddled, tunnelling or exteriorising of the pedicle, capillary refill or any congestion at the end of the procedure were recorded. In the immediate postoperative period the flap was monitored for any venous congestion or pallor. Functional and aesthetic outcome was noted in terms of complete or partial flap survival, successful coverage of the recipient defect, healing of any underlying fracture, ease or difficulty in walking or wearing shoes, ambulatory status of the injured limb after six months and any concerns of the patient regarding the aesthetic appearance of the flap and developement of useful sensations in the flap. Donor site healing or any complication was also recorded; loss of sensibility in the sural distribution area, i.e., the lateral side of the foot, any painful neuromas, or any concerns about the aesthetic disfigurement at the donor site. Patients were discharged on the 3rd postoperative day in case of uneventful recovery and called back on the 5th postoperative day to remove the graft dressing. They were followed for at least 6 months.

\section{Results:-}

Over the period of 10 years, a total of 100 distally based sural fasciocutaneous flaps were performed .Eighty patients were male while 20 were female. Their age ranged from 18 to 60 years, with a mean age of 35 years. Trauma was the cause of soft tissue defect in 52 patients; cancer resection in 17 patients, severe contracture release in 16 patients, and unstable scar and burn in 4 patient each,diabeties in 4 patients and chronic non healing ulcer in 3 patients( Table 1).

Table 1:-

\begin{tabular}{|c|c|c|}
\hline Etiology & No of patients & Percentage \\
\hline Trauma & 52 & $52 \%$ \\
\hline Tumour resection & 17 & $16 \%$ \\
\hline Severe Contracture & 16 & $4 \%$ \\
\hline Unstable Scar & 4 & $4 \%$ \\
\hline Burn & 4 & $4 \%$ \\
\hline Diabetes & 4 & $3 \%$ \\
\hline Ch. Nonhealing ulcer & 3 & $100 \%$ \\
\hline Total & 100 & 16,1 t \\
\hline
\end{tabular}

The site of the defect was distal third of the leg in 36 patients, heel in 20, medial malleolus in 16 , lateral malleolus in 12, and 8 each for exposed achilles tendon and dorsum of foot (Table 2).

Table 2:-

\begin{tabular}{|c|c|c|}
\hline Site of defect & No of patients & Percentage \\
\hline Lower third of leg & 36 & $26 \%$ \\
\hline Heel & 20 & $16 \%$ \\
\hline Medial Malleolus & 16 & $12 \%$ \\
\hline Lateral Malleolus & 12 & $8 \%$ \\
\hline Dorsum of Foot & 8 & $8 \%$ \\
\hline
\end{tabular}




\begin{tabular}{l|l|r} 
Total & 100 & $100 \%$
\end{tabular}

The dimensions of the flap ranged from 6-12 cm in length and from $4-8 \mathrm{~cm}$ in width. The mean length was $8.4 \mathrm{~cm}$ and mean width $5.7 \mathrm{~cm}$ table 3.88 flaps were islanded while 12 flaps were harvested with skin paddle. The flaps for defects on the distal leg, Achilles tendon, malleolus and posterior non weight bearing heel, were designed lower in the leg in its middle third and the flaps proximal limit did not encroach the upper third of the leg. The remaining flaps were designed higher in the proximal third of the leg and a gastrocnemius cuff was included in the upper part of the flap. The pivot point was kept $5 \mathrm{~cm}$ proximal to the tip of lateral malleolus in all cases. Out of 100 flaps, 80 showed complete survival (80\%). Partial flap loss (up to one third but less than half of the flap) was found in 3 patients (3\%) with anterior weight bearing heel and dorsum of foot defects; marginal flap necrosis in 4 patients $(4 \%)$ with anterior tibial and anterior heel defect, venous congestion developed in 5 patients (5\%) and complete loss in 4 patients (4\%) with extensive heel injury. Donor site graft loss occurred in 2 patients $(2 \%)$ and wound infection was noted in patients $(2 \%)$ and haematoma formation in 1 patient table 4.

Table 3:-

\begin{tabular}{|c|c|c|}
\hline Flap Size & No of patients & Percentage \\
\hline $12 \times 4.5 \mathrm{~cm}$ & 8 & $8 \%$ \\
\hline $11 \times 8.5$ & 3 & $3 \%$ \\
\hline $11 \times 8 \mathrm{~cm}$ & 12 & $12 \%$ \\
\hline $10 \times 8$ & 5 & $5 \%$ \\
\hline $8 \times 7.5 \mathrm{~cm}$ & 20 & $20 \%$ \\
\hline $7.5 \times 5.5 \mathrm{~cm}$ & 16 & $16 \%$ \\
\hline $6 \times 5.5 \mathrm{~cm}$ & 6 & $6 \%$ \\
\hline $6 \times 5 \mathrm{~cm}$ & 30 & $30 \%$ \\
\hline Total & 100 & $100 \%$ \\
\hline
\end{tabular}

Table 4:-

\begin{tabular}{|c|c|c|c|}
\hline Complications & No of patients & Percentage & Salvage Procedure \\
\hline Venous congestion & 5 & $5 \%$ & Elevation of part \\
\hline Complete flap loss & 4 & $4 \%$ & Debridement, and STSG \\
\hline Partial flap loss & 3 & $3 \%$ & $\begin{array}{c}\text { Debridement and healing by } \\
\text { secondary intention }\end{array}$ \\
\hline Marginal necrosis & 3 & $3 \%$ & $\begin{array}{c}\text { Daily dressings and healing by } \\
\text { sec intention }\end{array}$ \\
\hline Donor site graft loss & 2 & $2 \%$ & Healing by sec intention \\
\hline Wound infection & 2 & $2 \%$ & ASD + antibiotics \\
\hline Haematoma & 1 & $1 \%$ & $\begin{array}{c}\text { Exploration, drainage and } \\
\text { cauterisation of bleeders }\end{array}$ \\
\hline Total & 20 & $20 \%$ & \\
\hline
\end{tabular}

In all patients with complete survival of the flap and those with marginal necrosis (the necrosed area was debrided, flap advanced and resutured to the defect margins) successful coverage of the defect was achieved. Healing of tibial fractures was noted in all but one patient where later chronic osteomyelitis required raising of the flap and debriding the infected bone. Out of the heel flaps one needed debulking later, for easy fit in the shoes. Rest did not have any problem with wearing shoes. The patients did not experience any difficulty in walking after coverage of the anterior weight bearing heel defects. Most of the patients especially where chronic exposure was a problem, found a relief in the coverage of the defect. Eight patients (8\%) with the flaps for lateral malleolus and Achilles tendon coverage were concerned about the appearance of the flap. They were later serially debulked. In all cases the donor site showed uneventful recovery and good graft take. None complained of any painful neuromas or showed any concern about the sensory loss over the lateral aspect of the foot. Esthetically 32 patients found the donor site appearance of concern while the rest 68 were not bothered.

\section{Discussion:-}

Reconstruction of the lower leg and foot continues to be one of the most challenging tasks for the reconstructive plastic surgeon. An unreliable lower limb subdermal plexus translates to notoriously poor wound healing using 
cutaneous flaps (11). Following the developments in flap surgery, pedicled fasciocutanous flaps and free flaps have been used. The introduction of distally based sural fasciocutaneous flap provides reliable and effective method to cover skin defects of distal leg, foot and ankle. $(9,13)$ The defects reported in the literature that needed repair, include those resulting from road traffic accidents, non healing skin wounds, chronic venous ulcers, chronic osteomyelitis in diabetics, contractures, gangrene, unstable scars, cancer resections, and electrical burns. $(6,12)$ The major cause of defects in our patients included trauma due to road traffic accidents, similar to some other studies. $(2,7)$ The lower leg and heel were the most frequently involved sites in our study. The flap can be used to cover exposed vessels, bones, tendons, and internal fixation hardware. It has been shown to be more reliable and a better choice than the lateral supramalleolar flap (another distally based fasciocutaneous flap used in the distal lower extremity). The flap has been shown to be successful in diabetic and medically compromised patient. (15) Anterior and posterior tibial vessels occlusion and varicose leg veins are not considered an absolute contraindication to the use of a distally based sural flap. $(8,14)$ An occluded peroneal artery is however considered a contraindication. We noted complete flap survival in $80 \%$ of our patients, partial flap loss in $4 \%$, marginal necrosis in $3 \%$ and complete loss in $4 \%$, being comparable to other studies. Successful coverage of the defect was achieved in our study in (88\%) of patients: complete survival $80 \%$ and marginal necrosis $3 \%$ (the necrosed area was debrided, flap advanced and resutured to the defect). A meta-analysis of 50 articles that report the use of 720 distally based sural flaps, suggested $82 \%$ success rate of the flap. Complete flap necrosis was reported in $3.3 \%$, and partial or marginal flap necrosis in $11 \%$. (16) Similarly, a detailed retrospective analysis of sural flap complication rate was recently performed on a series of 70 consecutive flaps. The complication rate reported was 59\% (41 of 70 flaps), partial necrosis was noted in $17 \%$ and complete necrosis in 19\% flaps. (17) Akhtar (2) in his study of 84 patients observed flap survival in $78.5 \%$, partial necrosis in $16.5 \%$ and complete necrosis in $9.5 \%$. The flaps that showed marginal or partial necrosis showed postoperative congestion. One of these was used for anterior tibial defect while others were for heel and dorsum of foot defects. Various techniques have been adopted to increase the blood flow and hence the survival of the flap. These are: keeping the pedicle at least $4 \mathrm{~cm}$ wide, including a gastrocnemius muscle cuff especially when the flap is designed higher in the leg and sural flap delay procedures especially when large flaps are planned or if very distal foot defects need coverage. (18-21) Al-Qattan has also used the muscle cuff as a plug for small lower limb defects following debridement of infected/necrotic bone. (22,23) We included gastrocnemius muscle cuff when the flap was raised from higher in the leg, delayed one flap and kept the pedicle width to a minimum of $4 \mathrm{~cm}$ in all cases. The complete survival observed in our flaps used over the anterior heel or dorsum of foot defects could be due to these modifications. The flaps that showed complete loss in our study were in patients with extensive heel defect due to a road traffic accident. We suspect that due to the shearing and avulsion of surrounding tissues the perforator $5 \mathrm{~cm}$ proximal to the lateral malleolus, which was the point where we pivoted the flaps, might have been injured. Many studies have shown the usefulness of Doppler in such cases. (16) It is therefore recommended that in cases with extensive trauma, Doppler identification of the perforators be done before deciding on the pivot point. Many studies have suggested that venous congestion, and not lack of arterial supply, is the most significant reason for flap necrosis. (17) The fundamental problem is the presence of venous valves that can prevent the retrograde flow of blood out of the flap in spite of the venous collateral vessels. The methods reported to improve venous outflow are exteriorising the pedicle (24), intermittent drainage of short saphenous vein (16), leaches, and the supercharging of the flap by anastomosing the proximal end of the lesser saphenous vein to a vein in the recipient defect (25). In our patients that experienced marginal or partial loss venous congestion was noted postoperatively. We exteriorized the pedicle if found the bridging skin tight or if congestion of the flap was noted after tunnelling of the pedicle. Notable improvement in the congestion of flaps was seen in these cases.

\section{Conclusion:-}

From our clinical experience, we conclude that the vascular supply of the sural artery flap is constant and reliable, elevation is quick and easy, flap has a vide arc of rotation, there is no sacrifice of any major artery of the limb, there is no need of any special instruments, has the potential to provide good protective sensation, no functional loss is encountered. There is very little donor site morbidity, only disadvantage is the ugly donor site. The flap is a good alternative to free tissue transfer, when the patients are not candidates for prolonged surgery or have a contraindication for microsurgery. The caveats for a successful flap are: through knowledge and understanding of the anatomy of flap, careful and meticulous dissection, inclusion of lesser saphenous vein, sural nerve and deep fascia with the flap and pedicle, absolute hemostasis, proper splintage and compliant patient. 

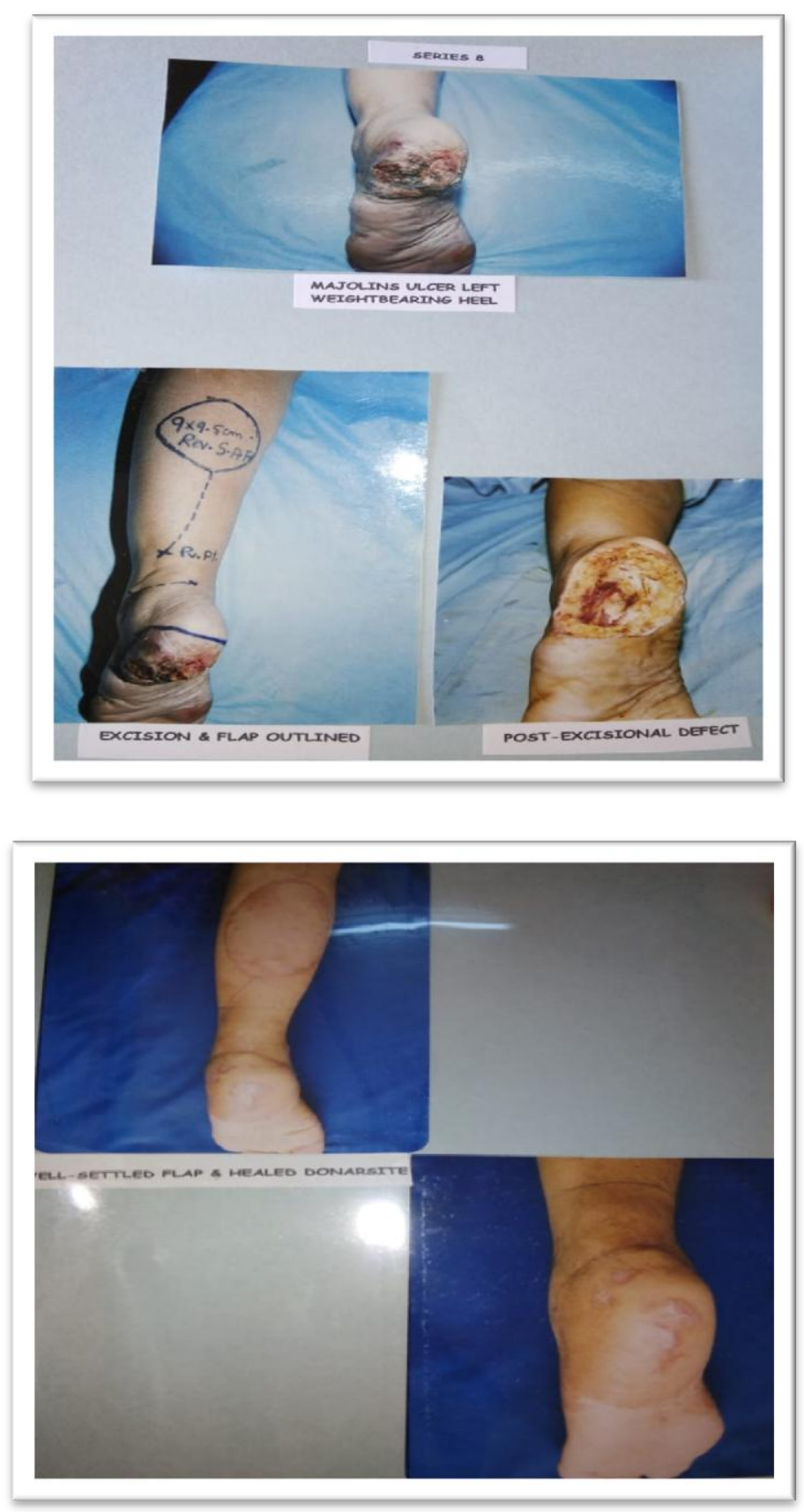

\section{Bibliography:-}

1. Fraccalvieri M, Boqetti P, Verna G, Carlucci S, Favi R, Bruschi S. Ditally based fasiocutaneous sural flap for foot reconstruction: a retrospective review of 10 years experience. Foot Ankle Int 2008;29:191-8.

2. Akhtar S, Hameed A. Versatility of the sural fasiocutaneous flap in the coverage of lower third leg and hind foot defects. J Plast Reconstr Aesthet Surg 2006;59:839-45.

3. $\mathrm{Xu} \mathrm{G}$, Jin LL. The coverage of skin defects over the foot and ankle using the distally based sural neurocutaneous flaps: Experience of 21 cases. J Plast Reconstr Aesthet Surg 2008;61:575-7.

4. Ahmed SK, Fung BK, Ip WY, Fok M, Chow SP. The versatile reverse flow sural artery neurocutaneous flap: A case series and review of literature. J Orthop Surg Res 2008;3(1):15-20.

5. Chen SL, Chen TM, Wang HJ. The distally based sural fasciomusculocutaneous flap for foot reconstruction. J Plast Reconstr Aesthet Surg 2006;59:846-55. 
6. Pirwani MA, Samo S, Soomro YH. Distally based sural artery flap: A workhorse to cover the soft tissue defects of lower 1/3 tibia and foot. Pak J Med Sci 2007;23:103-10.

7. Raveendran SS, Perera D, Happuharachchi T, Yoganathan V. Superficial sural artery flap-a study in 40 cases. J Plast Reconstr Aesthet 2004;57:266-9.

8. Hsieh CH, Liang CC, Kueh NS, Tsai HH, Jeng SF. Distally based sural island flap for the reconstruction of a large soft tissue defect in an open tibial fracture with occluded anterior and posterior tibial arteries-a case report. Br J Plast Surg 2005;58:112-5.

9. Masquelet AC, Romana MC, Wolf G. Skin island flaps supplied by the vascular axis of the sensitive superficial nerves: anatomic study and clinical experience in the leg. Plast Reconstr Surg 1992;89:1115-21.

10. Hasegawa M, Torji S, Katoh I, Esaki S. The distally based superficial sural artery flap. Plast. Reconstr. Surg 1994;93:1012-6.

11. Hallock GG. Lower extremity muscle perforators flap for lower extremity reconstruction. Plast reconst Surg 2004;114:1123-30.

12. Chen SL, Chen TM, Chou TD, Chang SC, Wang HJ. Distally based sural fasciocutaneous flap for chronic osteomyelitis in diabetic patients. Ann Plast Surg 2005;54(1):44-8.

13. Mozafari N, Moosavizadeh SM, Rasti M. The distally based neurocutaneous sural flap: a good choice for reconstruction of soft tissue defects of lower leg, foot and ankle due to fourth degree burn injury.Burns 2008;34(3):406-11.

14. Cavadas PC, Bonanand E. Reverse-flow sural island flap in the varicose leg. Plast Reconstr Surg 1996;98:9012.

15. Koladi J, Gang RK, Hamza AA et al. Versatility of the distally based superficial sural flap for reconstruction of lower leg and foot in children. J Pediatr Orthop 2003;23:194-8.

16. Follmar KE, Baccarani A, Steffen P, Baumeister L, Levin S, Erdmann D. The distally based sural flap. Plast Reconstr Surg 2007;119:138-48.

17. Baumeister SP, Spierer R, Erdmann D et al. A realistic complication analysis of 70 sural artery flaps in a multimorbid patient group. Plast Reconstr Surg 2003;112:129-40.

18. Chen SL, Chen TM, Wang HJ. The distally based sural fasciomusculocutaneous flap for foot reconstruction. J Plast Reconstr Aesthet Surg 2006;59:846-55.

19. Foran MP, Schreiber J, Christy MR, Goldberg NH, Silverman RP. The modified reverse sural artery flap for lower extremity reconstruction. J Trauma 2008;64:139-43.

20. Tosun ZO", zkan A, Karacor Z, Savaci N. Delaying the reverse sural flap provides predictable results for complicated wounds in diabetic foot. Ann Plast Surg 2005;55:169-73.

21. Ulrich MD, Bach, Alexander D, Polykandriotis E, Juergen K, Horch RE. Delayed Flap for Staged Reconstruction of the Foot and Lower Leg. Plast Reconstr Surg 2005;116:1910-7.

22. Al-Qattan MM. The reverse sural artery fasciomusculocutaneous flap for small lower-limb defects: the use of the gastrocnemius muscle cuff as a plug for small bony defects following debridement of infected/necrotic bone. Ann Plast Surg 2007;59:307-10.

23. Al-Qattan MM. The reverse sural fasciomusculocutaneous "mega-high" flap: a study of 20 consecutive flaps for lower-limb reconstruction. Ann Plast Surg 2007;58:513-6.

24. Maffi TR., Knoetgen J, TurnerNS, Moran SL. Enhancing survival using the distally based sural artery interpolation flap. Ann Plast Surg 2005;54:302-5.

25. Tan O, Atik B, Bekerecioglu M. Supercharged reverse-flow sural flap: a new modification increasing the reliability of the flap. Microsurgery 2005;25:36-43. 